\title{
Multitemporal Cross-Calibration of the Terra MODIS and Landsat 7 ETM+ Reflective Solar Bands
}

\author{
Amit Angal, Xiaoxiong Xiong, Member, IEEE, Aisheng Wu, \\ Gyanesh Chander, Member, IEEE, and Taeyoung Choi
}

\begin{abstract}
In recent years, there has been a significant increase in the use of remotely sensed data to address global issues. With the open data policy, the data from the Moderate Resolution Imaging Spectroradiometer (MODIS) and Enhanced Thematic Mapper Plus (ETM+) sensors have become a critical component of numerous applications. These two sensors have been operational for more than a decade, providing a rich archive of multispectral imagery for analysis of mutitemporal remote sensing data. This paper focuses on evaluating the radiometric calibration agreement between MODIS and ETM+ using the near-simultaneous and cloud-free image pairs over an African pseudo-invariant calibration site, Libya 4. To account for the combined uncertainties in the top-of-atmosphere (TOA) reflectance due to surface and atmospheric bidirectional reflectance distribution function (BRDF), a semiempirical BRDF model was adopted to normalize the TOA reflectance to the same illumination and viewing geometry. In addition, the spectra from the Earth Observing-1 (EO-1) Hyperion were used to compute spectral corrections between the corresponding MODIS and ETM+ spectral bands. As EO-1 Hyperion scenes were not available for all MODIS and ETM+ data pairs, MODerate resolution atmospheric TRANsmission (MODTRAN) 5.0 simulations were also used to adjust for differences due to the presence or lack of absorption features in some of the bands. A MODIS split-window algorithm provides the atmospheric water vapor column abundance during the overpasses for the MODTRAN simulations. Additionally, the column atmospheric water vapor content during the overpass was retrieved using the MODIS precipitable water vapor product. After performing these adjustments, the radiometric cross-calibration of the two sensors was consistent to within $7 \%$. Some drifts in the response of the bands are evident, with MODIS band 3 being the largest of about 6\% over 10 years, a change that will be corrected in Collection 6 MODIS processing.
\end{abstract}

Index Terms-Cross-calibration, landsat ETM+, Libya-4, MODTRAN, MODIS, water-vapor.

\section{INTRODUCTION}

$\mathbf{T}$ HE Moderate Resolution Imaging Spectroradiometer (MODIS) and Enhanced Thematic Mapper Plus (ETM+)

Manuscript received March 14, 2012; revised September 17, 2012 and December 2, 2012; accepted December 16, 2012. Date of publication February 11, 2013; date of current version March 21, 2013. Any use of trade, product, or firm names is for descriptive purposes only and does not imply endorsement by the U.S. Government.

A. Angal is with Science Systems and Applications Inc., Lanham, MD 20706 USA (e-mail: amit.angal@ssaihq.com).

$\mathrm{X}$. Xiong is with the Sciences and Exploration Directorate, NASA/GSFC, Greenbelt, MD 20771 USA (e-mail: Xiaoxiong.Xiong-1@ @asa.gov).

A. Wu and T. Choi are with Sigma Space Co., Lanham, MD 20706 USA (e-mail: aisheng.wu@ sigmaspace.com; tchoi@sigmaspace.com).

G. Chander is with SGT, Inc., Greenbelt, MD 20770 USA (e-mail: gchander@usgs.gov).

Color versions of one or more of the figures in this paper are available online at http://ieeexplore.iee.org.

Digital Object Identifier 10.1109/TGRS.2012.2235448 are two major Earth observing (EO) instruments flown aboard the Terra and Landsat 7 (L7) spacecrafts, respectively. The two sensors employ different calibration strategies for the reflective solar bands (RSBs). MODIS uses its onboard calibrators, the Solar Diffuser (SD) and the SD Stability Monitor (SDSM), to track its on-orbit degradation, plus regularly schedules lunar views to characterize the sensor response at different scan angles [1], [2]. ETM+ relies on a combination of onboard calibrators as well as vicarious calibration campaigns to track the on-orbit change of the sensor responses [3]-[5]. Since MODIS and ETM+ operate in orbits with matching Worldwide Reference System-2 ground tracks, repetitive medium resolution $(30 \mathrm{~m})$ and coarse spatial resolution $(250-1000 \mathrm{~m})$ observations of the Earth are possible. A synergistic use of the calibrated MODIS and ETM+ products can greatly benefit the science community by ensuring a high-quality global view of the Earth. Since launch, vicarious calibration/validation $(\mathrm{Cal} / \mathrm{Val})$ efforts were undertaken to evaluate the calibration consistency between the two sensors. Several field campaigns to cross-calibrate MODIS and ETM+ were conducted by the Remote Sensing Group, University of Arizona, Tucson, AZ, USA. Cross-calibration of various EO sensors (including Terra MODIS) with L7 ETM+ was performed over the Rail Road Valley Playa, NV, site, and the results indicated an agreement better than 5\% between the two sensors [5]. Over a decade of successful operation of the two sensors, a temporal crosscalibration between the two sensors is required in order to establish a comprehensive estimate of the differences in the observed measurements. Chander et al. [6], [7] selected the pseudo-invariant calibration sites in the Saharan desert to trend the long-term top-of-atmosphere (TOA) reflectance from the spectrally matching bands between two sensors. A reasonably consistent long-term agreement was observed in the longer wavelength bands; however, significant biases were evident in the MODIS band 3 and ETM+ band 1 pair. In addition, a need to compensate for the site bidirectional reflectance distribution function (BRDF) and the spectral mismatch between the two sensors was identified as the two major sources of uncertainty. In order to mitigate the impact due to site and atmospheric BRDF, a semiempirical BRDF model was developed for an accurate characterization of the long-term drift observed in both sensors [7]. Further efforts were undertaken to compensate for the spectral mismatch observed between the two sensors using hyperspectral measurements from Earth Observing-1 (EO-1) Hyperion which yielded significant improvement in the visible channels and adequate improvement in the longer wavelength short-wave infrared (SWIR) channels. Another key source of 
uncertainty arises from the varying atmospheric water vapor content and its impact on cross-calibration due to its sensitivity to the sensor's relative spectral response (RSR).

In order to perform an accurate cross-calibration between the two sensors, it is essential that the impacts due to spectral response mismatch, BRDF, atmospheric absorption features, etc., need to be addressed. The uncertainties due to these effects need to be characterized and compensated before a meaningful comparison between the two sensors can be performed. To address all of the above uncertainties, this paper formulates a technique for comparing the measured TOA reflectance from spectrally matching band pairs from these two sensors over a pseudo-invariant desert target using near-simultaneous observations.

Section II provides a detailed overview of the MODIS and ETM+ sensors, as well as the Libya 4 calibration site used for this paper. Section III presents the methodology used to derive the measured TOA reflectance trending over this site for both sensors. A semiempirical BRDF model is used to correct the impacts due to varying view geometry on the retrieved reflectance. Since both sensors have significantly different spectral response functions, a spectral mismatch correction based on hyperspectral observations from EO-1 Hyperion is formulated. Due to the limited availability of the near-simultaneous EO-1 Hyperion measurements, spectral mismatch correction based on MODerate resolution atmospheric TRANsmission (MODTRAN) 5.0 simulation is also developed [8], and the results were compared with Hyperion simulations. Due to the wider ETM+ spectral bands, the sensitivity to various water vapor absorption features needs to be accounted. A real-time correction for the impact of water vapor absorption on the retrieved TOA reflectance is formulated and applied to MODTRAN profiles. Section IV provides the results obtained from the various approaches formulated in Section III, and the last section provides a summary of this paper.

\section{Sensor And Site Overview}

The MODIS sensor aboard the Terra spacecraft was launched in December 1999 from Vandenberg Air Force Base (VAB), $\mathrm{CA}$, and has successfully operated on-orbit for over 12 years. The calibrated measurements from the 36 spectral bands, with wavelengths ranging from 0.41 to $14.5 \mu \mathrm{m}$, are used to generate over 40 science products [1]. There are two (bands 1 and 2) 250-m nadir spatial resolution bands, five (bands 3-7) 500-m nadir spatial resolution bands, and 29 (bands 8-36) 1-km nadir spatial resolution bands. Bands 1-19 and 26 are the RSBs. The RSB calibration is based on the regular measurements from the SD and SDSM, in addition to the monthly scheduled lunar observations. The measurements from the SD and SDSM are used for absolute calibration, whereas the lunar measurements along with the SD measurements are used to track the on-orbit response versus scan angle change. A $2 \%$ uncertainty requirement is specified for the MODIS TOA reflectance products, and $5 \%$ uncertainty is specified for the MODIS at-sensor spectral radiance products for observations made within $\pm 45^{\circ}$ viewing angles [1]. Due to a change in operational configuration, the SD door has been in an open position since July 2, 2003, which has led to an increased exposure of the SD to sunlight and, in turn, a relatively large rate of degradation. The SWIR bands of Terra MODIS (bands 5-7 and 26) experience an out-ofband thermal leak as well as electronic crosstalk. A correction algorithm has been developed and implemented in the level $1 \mathrm{~B}$ code since launch; however, residual effects are still evident in the Earth-scene imagery. Consequently, an additional $1 \%$ uncertainty is included for the SWIR bands [1], [2]. All of the MODIS granules used in this paper were processed using the Collection 5 Level 1B algorithm.

Now operational over a decade, the ETM+ sensor aboard the L7 spacecraft was launched in April 1999 from VAB. The L7 spacecraft flies about $30 \mathrm{~min}$ ahead of the Terra spacecraft in the same A.M. orbit. The on-orbit radiometric stability of ETM+ is tracked using a combination of on-orbit calibrators as well as vicarious measurements. The onboard calibrators include the use of the sun as a radiation source to regularly perform the full aperture solar calibration and partial aperture solar calibration. In addition, pseudo-invariant desert targets (Sudan 1, Mauritania 1/2, Arabia1, and Libya 4) are used to track the change in the sensor's gain on-orbit. A detailed description regarding the sensor's on-orbit radiometric performance can be found in [3]-[5]. A 5\% uncertainty requirement is specified for the ETM+ RSB at-sensor radiance [4]. Table I summarizes the key features of both MODIS and ETM+ sensors and their RSBs used for this paper. The following key observations can be made: 1) The MODIS swath is significantly wider than ETM+; 2) MODIS bandpass is significantly narrower than the corresponding ETM+ bandpasses; 3) the equatorial crossing time of the two sensors generally varies between $30 \mathrm{~min}$, and since both sensors are in the same A.M. orbit, it essentially implies that there will be a near-simultaneous nadir overpass between the two sensors once every 16 days; and 4) the ETM+ data are fundamentally calibrated in radiance, and the MODIS data are fundamentally calibrated in reflectance, so in order to compare them, a conversion needs to be done that involves a band-specific mean exoatmospheric solar irradiance $\left(\mathrm{ESUN}_{\lambda}\right)$ value that has added uncertainty. ETM+ advertises solar irradiance values based on Thuillier [4]; MODIS provides solar irradiance values based on a combination of Thuillier and Neckel and Labs [2]. The RSR of each MODIS and ETM+ band was convolved with both solar irradiance profiles to compute the in-band irradiance ( $E_{\text {sim }}^{\mathrm{MODIS}}$ and $\left.E_{\text {sim }}^{\mathrm{ETM}+}\right)$. A ratio of the in-band irradiance $\left(E_{\mathrm{sim}}^{\mathrm{MODIS}} / E_{\mathrm{sim}}^{\mathrm{ETM}+}\right)$ is calculated with the MODIS and ETM+ solar irradiance models for each spectrally matching band pair and is summarized in Table II. The differences induced due to different solar irradiance models is extremely small (within $0.1 \%$ ) for the VIS/NIR bands in comparison to the SWIR band pair. The major impact of about $2.04 \%$ is observed in the band 7 pair, and this additional uncertainty has to be considered in the comparison of TOA reflectances between the two sensors.

A set of radiometrically stable and bright desert targets from the Saharan and Arabian deserts was identified by Cosnefroy et al. [9]. The Committee on Earth Observation Satellites has recommended six pseudo-invariant desert sites (Libya 4, Mauritania 1, Mauritania 2, Algeria 3, Libya 1, and Algeria 5) from the Saharan desert. The Libya $4\left(28.55^{\circ} \mathrm{N}\right.$, 
TABLE I

SENSOR CHARACTERISTICS

\begin{tabular}{|c|c|c|c|c|}
\hline Parameter & \multicolumn{2}{|c|}{ Terra MODIS } & \multicolumn{2}{|c|}{ Landsat 7 ETM+ } \\
\hline Launched & Dec & mber, 181999 & & ril 15,1999 \\
\hline Equator crossing time & & 0 AM (local) & $10: 00$ & 0:15 AM (local) \\
\hline Swath & & $2330 \mathrm{~km}$ & & $187 \mathrm{~km}$ \\
\hline Altitude & & $705 \mathrm{~km}$ & & $705 \mathrm{~km}$ \\
\hline Pixel quantization & & 12 bit & & 8 bit \\
\hline Bandwidth & $\begin{array}{c}\text { MODIS } \\
\text { bands } \\
3 \\
4 \\
1 \\
2 \\
6 \\
7 \\
\end{array}$ & $\begin{array}{c}\text { Bandpass }(\mu \mathbf{m}) \\
0.459-0.479 \\
0.545-0.565 \\
0.620-0.670 \\
0.841-0.876 \\
1.628-1.652 \\
2.105-2.155 \\
\end{array}$ & $\begin{array}{c}\text { ETM+ } \\
\text { bands } \\
1 \\
2 \\
3 \\
4 \\
5 \\
7 \\
\end{array}$ & $\begin{array}{c}\text { Bandpass }(\mu \mathrm{m}) \\
0.452-0.514 \\
0.519-0.601 \\
0.631-0.692 \\
0.772-0.898 \\
1.547-1.748 \\
2.065-2.346 \\
\end{array}$ \\
\hline Spatial Resolution & $\begin{array}{c}\text { MODIS } \\
\text { bands } \\
3 \\
4 \\
1 \\
2 \\
6 \\
7 \\
\end{array}$ & $\begin{array}{c}\text { Res (m) } \\
500 \\
500 \\
250 \\
250 \\
500 \\
500 \\
\end{array}$ & $\begin{array}{c}\text { ETM+ } \\
\text { bands } \\
\mathbf{1} \\
\mathbf{2} \\
\mathbf{3} \\
4 \\
\mathbf{5} \\
7 \\
\end{array}$ & $\begin{array}{c}\text { Res }(\mathbf{m}) \\
30 \\
30 \\
30 \\
30 \\
30 \\
30 \\
\end{array}$ \\
\hline $\begin{array}{c}\text { Exoatmospheric Solar } \\
\text { Spectral Irradiance (Esun) }\end{array}$ & $\begin{array}{c}\text { MODIS } \\
\text { bands } \\
3 \\
4 \\
1 \\
2 \\
6 \\
7 \\
\end{array}$ & $\begin{array}{c}\operatorname{Esun}_{\lambda}\left(\mathbf{W} / \mathbf{m}^{2}-\boldsymbol{\mu m}\right) \\
2087.94 \\
1865.94 \\
1606.17 \\
992.2 \\
240.23 \\
90.33 \\
\end{array}$ & $\begin{array}{c}\text { ETM+ } \\
\text { bands } \\
1 \\
2 \\
3 \\
4 \\
5 \\
7 \\
\end{array}$ & $\begin{array}{c}\operatorname{Esun}_{\lambda}\left(\mathbf{W} / \mathbf{m}^{2}-\boldsymbol{\mu m}\right) \\
1997 \\
1812 \\
1533 \\
1039 \\
230.8 \\
84.9 \\
\end{array}$ \\
\hline
\end{tabular}

TABLE II

Ratio of In-BAND IRRAdiance Calculated With MODIS AND ETM+ Solar IRRADiance

\begin{tabular}{|c|c|c|c|c|c|c|}
\hline Sensor/Band & $\begin{array}{c}\text { ETM+ } \\
\text { B1 }\end{array}$ & $\begin{array}{c}\text { ETM+ } \\
\text { B2 }\end{array}$ & $\begin{array}{c}\text { ETM+ } \\
\text { B3 }\end{array}$ & ETM+ B4 & $\begin{array}{c}\text { ETM+ } \\
\text { B5 }\end{array}$ & $\begin{array}{c}\text { ETM+ } \\
\text { B7 }\end{array}$ \\
\hline MODIS ESUN & 1.031 & 1.015 & 1.027 & $\mathbf{0 . 9 3 8}$ & $\mathbf{1 . 0 3 8}$ & $\mathbf{1 . 1 8 7}$ \\
\hline ETM+ ESUN & 1.031 & 1.015 & 1.028 & $\mathbf{0 . 9 3 6}$ & $\mathbf{1 . 0 3 5}$ & $\mathbf{1 . 1 6 3}$ \\
\hline \% difference & $\mathbf{0 . 0 2 9}$ & $\mathbf{0 . 0 1 2}$ & $\mathbf{0 . 0 6 4}$ & $\mathbf{0 . 1 6 9}$ & $\mathbf{0 . 2 6 0}$ & $\mathbf{2 . 0 4 4}$ \\
\hline
\end{tabular}

$\left.23.39^{\circ} \mathrm{E}\right)$ site is made up of sand dunes with a low aerosol loading and practically no vegetation [9]. The ground truth information from these test sites can be propagated through the atmosphere using radiative transfer to predict the TOA reflectance. However, acquiring the ground measurements can be labor intensive and is a relatively costly process. Since Libya 4 is known to be a temporally, spatially, and spectrally stable target, recurring observations over the site bypass the requirement for ground truth information for sensor cross-calibration. Due to the above characteristics, the Libya 4 site has been widely used to monitor the on-orbit calibration of the Advanced Very High Resolution Radiometer family of sensors [10]. Fig. 1 shows an image acquired by L7 ETM+ over the Libya 4 desert region on May 25, 2001. The true color image is generated using a combination of L7 ETM+ bands 1-3 at the native spatial resolution of $30 \mathrm{~m}$. The MODIS half kilometer product is a combination of MODIS bands 1, 2, and 4 and is used along with the geolocation information to present a typical nearsimultaneous acquisition between the two sensors.

\section{Methodology}

\section{A. TOA Reflectance Calculation}

Terra MODIS Level 1B (L1B) Collection 5 calibrated TOA radiance and reflectance $250-\mathrm{m}$ (MOD02QKM) products were

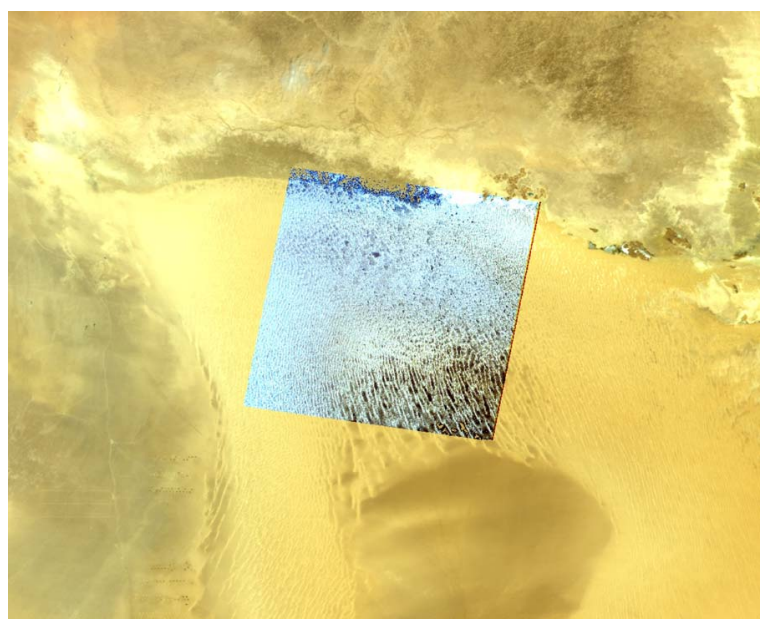

Fig. 1. Libya 4 desert region acquired from L7 ETM+ and Terra MODIS with spatial resolutions of 30 and $500 \mathrm{~m}$ on May 25, 2001. A MODIS band combination of $3,2,1$ is used.

used for MODIS bands 1 and 2, and MODIS L1B $500 \mathrm{~m}$ (MOD02HKM) products were used for MODIS bands 3, 4, 6, and 7. The ETM+ products were mapped to a Universal Transverse Mercator (UTM) grid map projection in GeoTiff format. To overcome the registration inconsistency between the two products, geometric corrections need to be applied to the 

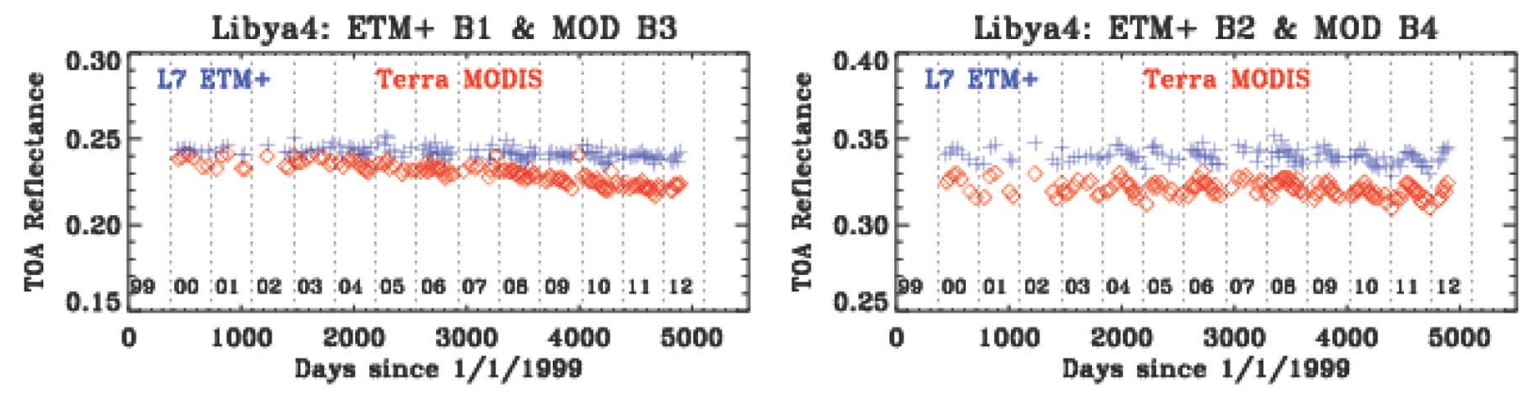

Libya4: ETM+ B3 \& MOD B1

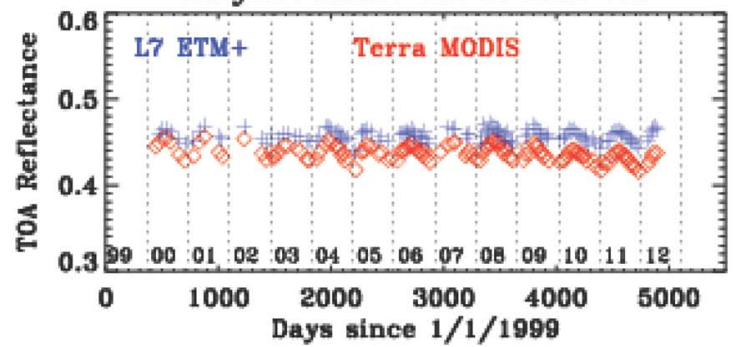

Libya4: ETM+ B4 \& MOD B2

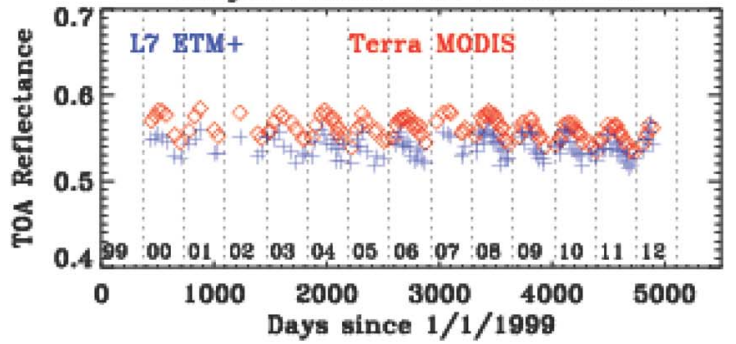

Libya4: ETM+ B5 \& MOD B6
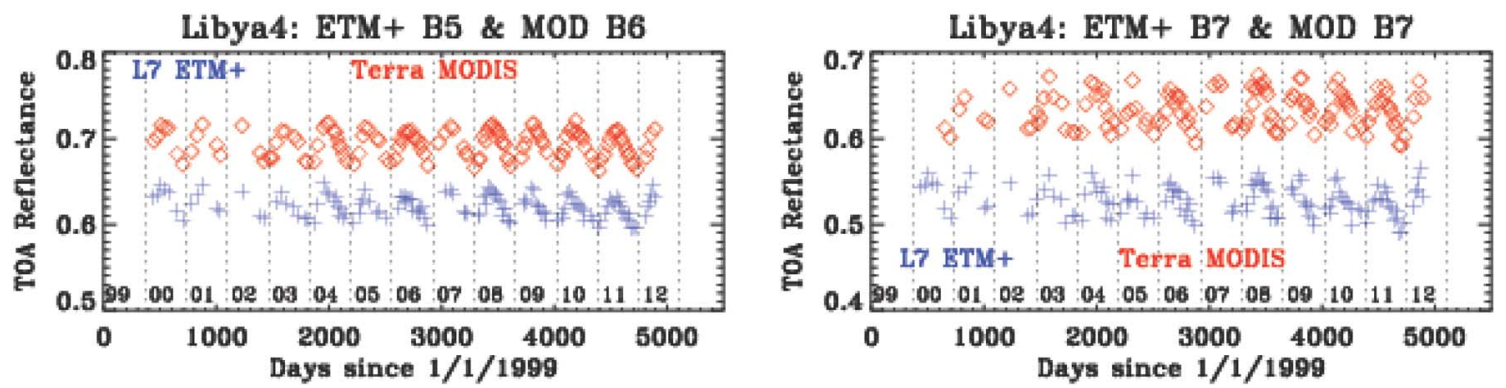

Fig. 2. Measured TOA reflectance trending for the spectrally matching MODIS and ETM+ bands.

MODIS L1B product. The MODIS Reprojection Tool Swath (MRTSwath) was used to apply the ETM+ map projection to the MODIS L1B products [6]. The output images from MRTSwath are rotated so that they are oriented to UTM North, as shown in Fig. 1.

Selection of a uniform region of interest (ROI) is vital in minimizing the impacts on the TOA reflectance due to the variability in the ROI. Lachérade et al. [12] evaluated the spatial uniformity of the African and Arabian test sites and selected a uniform region of about $100 \mathrm{~km} \times 100 \mathrm{~km}$ centered on the Libya 4 coordinates $\left(28.55^{\circ} \mathrm{N}, 23.39^{\circ} \mathrm{E}\right)$, showing a variability of about $2 \%$ in the visible and near-infrared (VNIR) bands [11]. Using this information, a smaller subset of around $20 \mathrm{~km} \times$ $20 \mathrm{~km}$ centered on the Libya 4 site coordinates was chosen. In this paper, the TOA reflectance for both sensors is computed using all of the valid pixels in the selected ROI. For ETM+, the pixels impacted by the scan line corrector (SLC) are flagged and are excluded from the calculations. The sensor-specific parameters $\left(\mathrm{ESUN}_{\lambda}\right.$, solar zenith, etc.) were used in the TOA reflectance calculations. A detailed description of the process can be found in [6]. Over 10+ years of near-simultaneous overpasses between the two sensors was processed, prompting a need to implement an automatic cloud-cover rejection methodology. A methodology using the atmospheric window channels (11 and $12 \mu \mathrm{m}$ ) was previously demonstrated to discriminate the brightness temperature (BT) of cloud pixels with the BT from the hot desert pixels [13]. In general, the BT retrieved by the atmospheric window channels, viewing the Libya 4 desert scene, exceeds $300 \mathrm{~K}$. The MODIS cloud mask product has a restoral test that classifies a desert scene as "confident clear" if the BT of band $31(11 \mu \mathrm{m})$ channel exceeds $302.5 \mathrm{~K}$. An average BT for band 31 was computed over the selected ROI, and scenes failing this criterion were excluded from further analysis.

Fig. 2 shows the long-term measured TOA reflectance trending for the spectrally matching bands of Terra MODIS (red diamonds) and L7 ETM+ (blue plus) over the Libya 4 site. Since only near-nadir scenes are chosen for this analysis and the repeat cycle of L7 is 16 days, a near-simultaneous pair between the two sensors can be obtained once every 16 days. Although Terra was launched nearly a year after L7, the number of nadir MODIS scenes exceeds the number of ETM+ scenes because of the limited duty cycle of L7, in addition to the lost data due to the nonavailability of a ground station for data-downlink, storage limitations on the solid space recorder, and interruption in the data acquisition during the SLC anomaly and bumper mode transition. Prior to any filtering for clouds, a total of 276 near-nadir scenes from Terra MODIS and 175 scenes from L7 ETM+ were processed to compute the TOA reflectance. The timeline of the acquisitions of both sensors spans from launch to July 2012. Table III provides a summary of the total number of scenes used in the analysis. A total of 167 near-simultaneous pairs between ETM+ and MODIS over Libya 4 are available, which are further reduced to 133 after excluding the scenes 
TABLE III

SUMMARY OF TERRA MODIS AND L7 ETM+ OVER LIBYA 4

\begin{tabular}{|c|c|c|c|c|c|c|c|c|c|c|c|c|c|c|}
\hline Year & 1999 & $\mathbf{2 0 0 0}$ & $\mathbf{2 0 0 1}$ & $\mathbf{2 0 0 2}$ & $\mathbf{2 0 0 3}$ & $\mathbf{2 0 0 4}$ & $\mathbf{2 0 0 5}$ & $\mathbf{2 0 0 6}$ & $\mathbf{2 0 0 7}$ & $\mathbf{2 0 0 8}$ & $\mathbf{2 0 0 9}$ & $\mathbf{2 0 1 0}$ & $\mathbf{2 0 1 1}$ & $\mathbf{2 0 1 2}$ \\
\hline ETM+ & $\mathbf{2}$ & $\mathbf{8}$ & $\mathbf{8}$ & $\mathbf{6}$ & $\mathbf{1 0}$ & $\mathbf{1 3}$ & $\mathbf{1 1}$ & $\mathbf{1 8}$ & $\mathbf{1 2}$ & $\mathbf{2 1}$ & $\mathbf{1 7}$ & $\mathbf{2 0}$ & $\mathbf{2 0}$ & $\mathbf{9}$ \\
\hline MODIS & $\mathbf{0}$ & $\mathbf{1 8}$ & $\mathbf{2 2}$ & $\mathbf{2 1}$ & $\mathbf{2 3}$ & $\mathbf{2 3}$ & $\mathbf{2 3}$ & $\mathbf{2 2}$ & $\mathbf{2 3}$ & $\mathbf{2 2}$ & $\mathbf{2 3}$ & $\mathbf{2 2}$ & $\mathbf{2 3}$ & $\mathbf{1 1}$ \\
\hline SNO & $\mathbf{0}$ & 7 & 7 & 4 & $\mathbf{1 0}$ & $\mathbf{1 3}$ & $\mathbf{1 1}$ & $\mathbf{1 8}$ & $\mathbf{1 2}$ & $\mathbf{2 0}$ & $\mathbf{1 7}$ & $\mathbf{1 9}$ & $\mathbf{2 0}$ & $\mathbf{9}$ \\
\hline $\begin{array}{c}\text { SNO } \\
\text { (filter) }\end{array}$ & $\mathbf{0}$ & 7 & $\mathbf{5}$ & $\mathbf{3}$ & $\mathbf{7}$ & $\mathbf{1 2}$ & $\mathbf{9}$ & $\mathbf{1 5}$ & $\mathbf{7}$ & $\mathbf{1 7}$ & $\mathbf{1 1}$ & $\mathbf{1 7}$ & $\mathbf{1 7}$ & $\mathbf{6}$ \\
\hline
\end{tabular}

contaminated with clouds. The long-term drift in the shorter wavelength band pair (ETM+ B1 and MODIS B3) is evident, with more degradation seen in the MODIS trends. A clear offset between the measured TOA reflectance trends of both sensors can be attributed to the different contributions of the ground spectral signature and atmospheric composition to the RSR, and the possible differences caused by calibration. The seasonal oscillations, largely caused by the site-specific BRDF, are more predominant (greater than 5\%) in the SWIR wavelength than the VNIR bands. The large magnitude of these oscillations seen in both sensors must be addressed before an estimation of the calibration difference between the two sensors is performed. In order to evaluate the long-term stability of the two sensors, a set of linear regressions was fitted to the ETM+ and MODIS TOA reflectance data, and a T-test was performed. The results from the Libya 4 site suggest that the current ETM+ radiometric calibration is stable for all bands except band 1 and band 3. Similarly, the results from the Libya 4 site suggested that the current MODIS radiometric calibration is stable for all bands except MODIS band 3. For other bands, results do not show significant long-term change over the 10 years of the mission [6].

\section{B. Site BRDF Characterization}

The surface and atmospheric BRDFs may significantly impact the measured TOA reflectance derived by each sensor. The physical BRDF models which require information regarding the site during the acquisition are often more complex and many need in situ data and topographic information. In the following study, the aim is to minimize the temporal impacts on the TOA reflectance trending by deriving the BRDF model parameters from the measurements themselves. A semiempirical model formulated by Roujean et al. [14] is expressed so that the bidirectional reflectance is a linear combination of three terms weighted by the following three parameters: 1) an isotropic function accounting for the bidirectional reflectance with nadir view and overhead sun; 2) a geometric function accounting for the effects of shadows and geometrical structures; and 3) a volume scattering component. The modeled bidirectional reflectance $R$ for each band can be expressed as

$$
R\left(\theta_{s}, \theta_{v}, \phi\right)=k_{0}+k_{1} f_{1}\left(\theta_{s}, \theta_{v}, \phi\right)+k_{2} f_{2}\left(\theta_{s}, \theta_{v}, \phi\right)
$$

where $\theta_{s}, \theta_{v}$, and $\phi$ denote the solar zenith, view zenith, and relative azimuth angles. The coefficients $k_{0}, k_{1}$, and $k_{2}$ are given as functions of parameters related to the physical structure and optical properties of the reflecting surface, and $f_{1}$ and $f_{3}$ are derived from the volume scattering component and geometric shadow casting theory, respectively. Due to high repeatability of MODIS granules over the Libya 4 site, MODIS measurements were chosen to empirically construct the BRDF model. One of the prerequisites for constructing an effective BRDF model is to use uncontaminated observations from a time period when the sensor's on-orbit calibration is stable and accurate. The time period from January 2002 to January 2004 was deemed suitable for this purpose, so all available MODIS scenes from this time period were chosen to derive the BRDF model coefficients. This time interval of two years during the early mission time of Terra MODIS was carefully chosen to cover a wide range of solar zenith angles. In addition, the impact of the long-term drift seen in the shorter wavelengths of Terra MODIS also bears a minimal impact in the derived coefficients. The coefficients $k_{0}, k_{1}$, and $k_{2}$ are computed using a least squares minimization of the differences between the observed and modeled reflectances using the corresponding view geometry parameters. Further details on the implementation of the model can be found in [13]. These coefficients are then used to derive the modeled reflectance for the MODIS band and the spectrally matching ETM+ bands [15]. The purpose of this normalization is to mitigate the impacts due to site-specific BRDF in order to obtain an accurate estimate of the spectral mismatch between the two sensors [16]. Applying the MODISbased BRDF model to normalize ETM+ observed reflectances has two advantages: first, it removes most of the BRDF impacts on ETM+ reflectance data, and second, it provides a direct assessment of relative biases between MODIS and ETM+ reflectance measurements.

\section{Spectral Mismatch Correction Using EO-1 Hyperion}

The differences in the TOA reflectance caused by the mismatch in spectral response of the two sensors can be compensated using a simulated TOA reflectance profile of the site during the overpass time using hyperspectral observations or radiative transfer model simulations [17]. This section describes a methodology that compensates for the RSR mismatch using hyperspectral observations using the EO-1 Hyperion measurements. EO-1 Hyperion, launched in November 2000, was designed to orbit about 1 min behind L7 ETM+ [18]. Since it was launched as a part of a technology validation mission, there has been a significant change in its orbit since 2006, which essentially means that the number of near-simultaneous overpasses between EO-1 Hyperion and L7 ETM+ has reduced dramatically [19]. Since launch, there have been only 28 nearsimultaneous overpass pairs between EO-1 Hyperion, Terra MODIS, and L7 ETM+. In order to sample various atmospheric absorption features such as water vapor, oxygen, and ozone during the overpass time, it is vital to have a near-simultaneous hyperspectral observation during every MODIS and ETM+ acquisition. Due to the limited number of near-simultaneous 


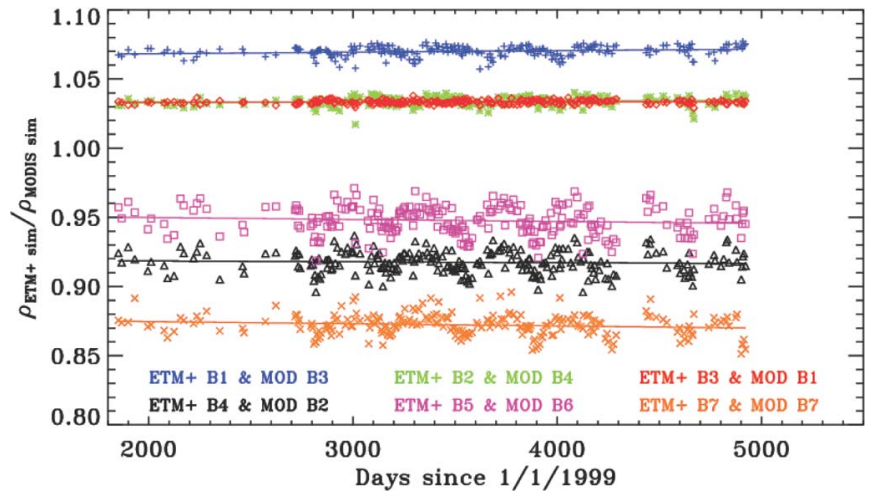

Fig. 3. SBAF derived using EO-1 Hyperion observations.

Hyperion observations, an alternative approach using all available (268) Hyperion scenes to derive a band-specific correction factor for the spectral mismatch is developed. The underlying assumption in this approach is that Libya 4 is a temporally and spectrally stable pseudo-invariant site and the various atmospheric absorption features are sampled repeatedly during every Hyperion acquisition. Since the swath of EO-1 Hyperion $(7 \mathrm{~km})$ is much smaller than ETM+ and MODIS, ROIs common to both MODIS and ETM+ scenes are chosen from each acquisition to obtain the hyperspectral profile. Using the sensor-specific RSR and the hyperspectral profile derived from every EO-1 Hyperion acquisition over Libya 4, the simulated TOA reflectance for each band of both sensors is obtained by integrating the RSR with the hyperspectral profile [20]. Hence, the correction for the differences in the TOA reflectance caused by the RSR mismatch between the two sensors can be expressed using the spectral band adjustment factor (SBAF)

$$
\begin{aligned}
\mathrm{SBAF} & =\frac{\bar{\rho}_{\lambda(\mathrm{ETM}+)}}{\bar{\rho}_{\lambda(\mathrm{MODIS})}} \\
& =\frac{\left(\int \rho_{\lambda} \operatorname{RSR}_{\lambda(\mathrm{ETM}+)} d \lambda\right) /\left(\int \operatorname{RSR}_{\lambda(\mathrm{ETM}+)} d \lambda\right)}{\left(\int \rho_{\lambda} \operatorname{RSR}_{\lambda(\mathrm{MODIS})} d \lambda\right) /\left(\int \operatorname{RSR}_{\lambda(\mathrm{MODIS})} d \lambda\right)}
\end{aligned}
$$

where $\operatorname{RSR}_{\lambda}$ denotes the RSR of the sensor, $\rho_{\lambda}=$ Hyperspectral TOA reflectance profile obtained using EO-1 Hyperion, $\bar{\rho}_{\lambda(\mathrm{ETM}+)}=$ Simulated TOA reflectance for sensor L7 ETM+, and $\bar{\rho}_{\lambda \text { (MODIS })}=$ Simulated TOA reflectance for Terra MODIS.

Fig. 3 shows the SBAF for all six band pairs derived using all available EO-1 Hyperion observations over the Libya 4 site. In general, the variation in the SBAF over time is within $0.5 \%$ for ETM+ bands $1-3$ and corresponding MODIS bands; however, fluctuations up to $3 \%$ are evident for the remaining band pairs. ETM+ bands 4, 5, and 7 have the presence of water vapor absorption features in their RSR which is absent from the corresponding MODIS bands 2, 6, and 7. During each acquisition, the variable amounts of atmospheric water vapor result in more fluctuations in the SBAF trending, as illustrated in Fig. 3. The long-term change in the SBAF trending for all of the bands pairs is seen to be generally within $0.5 \%$. Due to lack of availability of near-simultaneous Hyperion overpasses, a simple linear model can be used to perform a temporal SBAF correction for each of the ETM+ and MODIS near-simultaneous overpasses. However, to avoid the potential impacts due to a long-term degradation in the EO-1 Hyperion calibration, a constant band-pair-specific SBAF (average of SBAF over time) has been applied to the BRDF normalized reflectance ratio of MODIS and ETM+ to account for the differences caused by spectral mismatch. In general, the long-term drift observed in the SBAF trending derived from EO-1 Hyperion is relatively small $(<0.5 \%)$ in comparison to the actual SBAF adjustment.

In order to have an accurate estimate of the differences in the TOA reflectance caused by calibration errors in either sensor, an accurate correction for spectral mismatch should be performed. Using a linear model, as described previously, a first-order estimate of the spectral mismatch between the two sensors can be obtained; however, the day-to-day variations in the atmospheric conditions are not accounted for in such a correction due to a lack of near-simultaneous EO-1 Hyperion scenes. This impact will be more evident in the spectral channels with the presence of a water-absorption feature. In order to overcome this limitation and reliance on near-simultaneous hyperspectral acquisitions, MODTRAN 5.0 is used to simulate the hyperspectral profile over a desert with varying impacts of water vapor absorption [21].

\section{Spectral Mismatch Correction Using MODTRAN Simulation}

A typical reflectance spectrum over a desert target generated using MODTRAN 5.0 was used to estimate the RSR mismatch correction caused by variations in the columnar atmospheric water vapor content. MODTRAN can provide a spectral signature of a typical mid-latitude desert target at an improved spectral resolution of $1 \mathrm{~nm}$ compared to $10 \mathrm{~nm}$ EO-1 Hyperion. The high spectral resolution is vital in characterizing the impacts of the various water vapor absorption features on the retrieved TOA reflectance. Using the high-resolution spectral profile, the SBAF can be calculated for all spectrally matching band pairs of both sensors and can be applied to the BRDF normalized reflectance ratio of each band pair to evaluate the calibration difference. The EO-1 Hyperion-based SBAF will be accurate for the wavelengths which have no absorption features. However, as described earlier, ETM+ bands 4 and 5 have the presence of an absorption feature which is absent from the RSR of the spectrally matching MODIS bands. Because of this, forced inputs of columnar water vapor content have been used in MODTRAN simulation to evaluate the change on the retrieved spectral signature of the typical desert. Previous work from $\mathrm{Yu}$ and $\mathrm{Wu}$ [22] reported the typical water vapor concentration over the Libyan desert to be around $1.65 \mathrm{~g} / \mathrm{cm}^{2}$. The columnar atmospheric water vapor content varying from 0 to $6 \mathrm{gm} / \mathrm{cm}^{2}$ is used as a forced input to MODTRAN to generate a hyperspectral signature of the target. Fig. 4 shows the RSR of both sensors for the VNIR and SWIR bands. The MODIS RSR is shown in red, and the ETM+ RSR is shown in blue. A hyperspectral signature of a typical desert target generated using MODTRAN is also shown in both figures. Each color in the spectral signature represents the profile generated using a forced water vapor input [21]. The absorption features seen around $820 \mathrm{~nm}$, from 1700 to $1780 \mathrm{~nm}$, and from 2300 to 


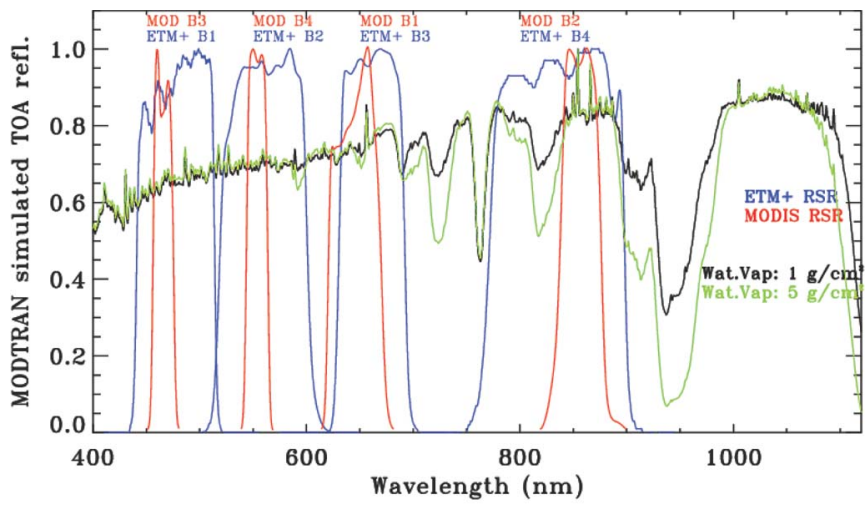

(a)

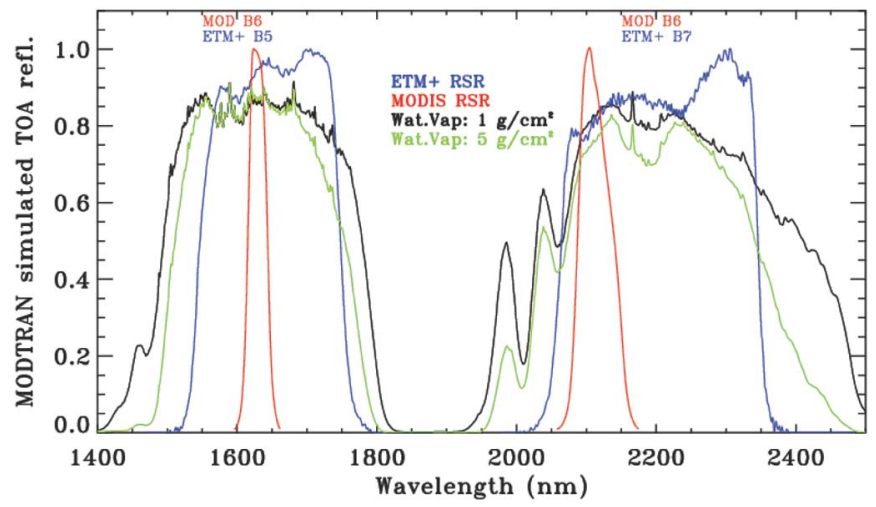

(b)

Fig. 4. Illustration of the impact of columnar water vapor on the retrieved hyperspectral profile using MODTRAN.

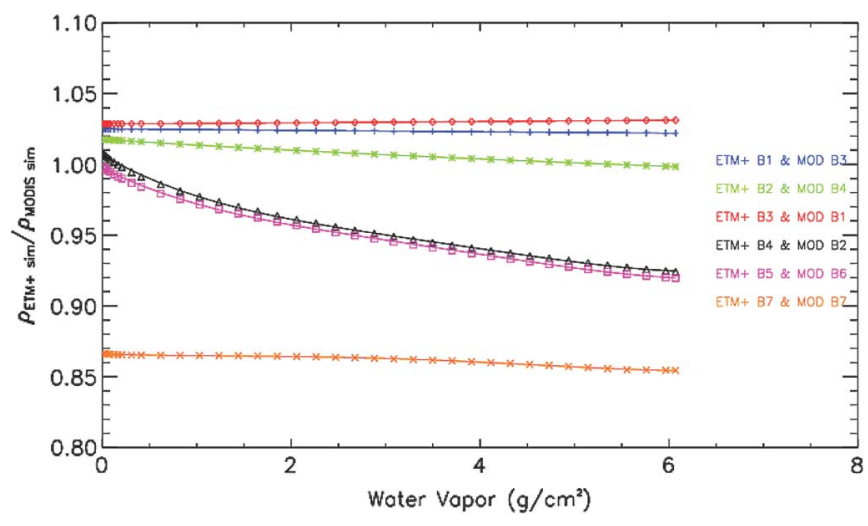

Fig. 5. Impact of water vapor on the SBAF using MODTRAN spectra for all spectrally matching bands.

near $2380 \mathrm{~nm}$ are included in the ETM+ RSR, thereby indicating that the amount of atmospheric water vapor content will bear an impact on the retrieved TOA reflectance trending. An SBAF value for all spectrally matching band pairs can be generated using each hyperspectral profile, thereby characterizing the impacts of the columnar atmospheric water vapor on the SBAF.

Fig. 5 shows the impact of atmospheric water vapor on the calculated SBAF using MODTRAN spectra, which is plotted as a function of water vapor. The impacts of water vapor absorption features present in ETM+ bands 4 and 5 are clearly evident, whereby the SBAF has a variation of up to $10 \%$ with variable water vapor in the atmosphere. ETM+ bands 1, 3, and 7, and corresponding MODIS bands show the least variation as a function of water vapor, and ETM+ band 2 and MODIS band 4 exhibit around 2\% variation in the SBAF. The SBAF values are also comparable with those derived using EO-1 Hyperion, as shown in Fig. 3. The results after the application of both the SBAFs will be discussed in the results section of this paper. With the availability of real-time information of the atmospheric water vapor during the exact overpass time of the two sensors derived from the MODIS water vapor product, an accurate correction for the RSR mismatch based on water vapor content can be applied and is discussed in the next section.

\section{E. Water Vapor Correction}

The split-window technique is widely used to retrieve the land surface temperature from satellite measurements [23]. The atmospheric effects can be characterized based on the differential absorption in adjacent infrared bands. MODIS band 32 $(12 \mu \mathrm{m})$ is more sensitive to atmospheric water vapor absorption than the adjacent MODIS band $31(11 \mu \mathrm{m})$. The difference between the BT retrieved from these two bands is indicative of the atmospheric water vapor content. A linear regression can be performed between the BT difference of the $11-\mu \mathrm{m}$ (MODIS band 31) and 12- $\mu \mathrm{m}$ (MODIS band 32) channels and the measured atmospheric water vapor content during the overpass time. The MODIS precipitable water vapor product (MOD05_L2) is used to derive the column atmospheric water vapor content over the Libya 4 site. These measurements are generated at a $1-\mathrm{km}$ spatial resolution of the MODIS instrument, and a detailed description of the product along with the associated algorithms can be found in [23]. All available MOD05_L2 measurements (Collection 5.1) over the Libya 4 site from launch to July 2012 were processed to extract the column atmospheric water vapor. The BT difference between the 11- and 12- $\mu \mathrm{m}$ MODIS channels for the corresponding scenes is also extracted, and a linear regression is performed to derive a relationship for estimating the water vapor in grams per square centimeter for any overpass time [24]. Fig. 6(a) shows the linear relationship between the atmospheric water vapor (in grams per square centimeter) and the BT difference between the two sensors. The variations in the atmospheric water vapor content over Libya 4 can be from 1 to about $4 \mathrm{~g} / \mathrm{cm}^{2}$, which bears about a 5\% change in the SBAF values of the ETM+ bands 4 and 5, as derived from Fig. 3. Using the real-time estimate of the column atmospheric water vapor and the SBAF trending relationship as a function of water vapor, as derived in Fig. 6(a), an SBAF value can be estimated using MODTRAN. For any given MODIS and ETM+ nearsimultaneous observation, the BT difference between the 11and $12-\mu \mathrm{m}$ channels is calculated to determine the SBAF, which is also a function of atmospheric water vapor content. Since this paper is restricted to only the near-simultaneous overpasses between ETM+ and MODIS, a preferred approach would be to derive the water vapor correction using the retrieved water vapor from the corresponding MOD05_L2 product, thereby bypassing the split-window technique. Intuitively, this approach should provide a more accurate characterization of the impact of water vapor on the SBAF; however, a comparison with 


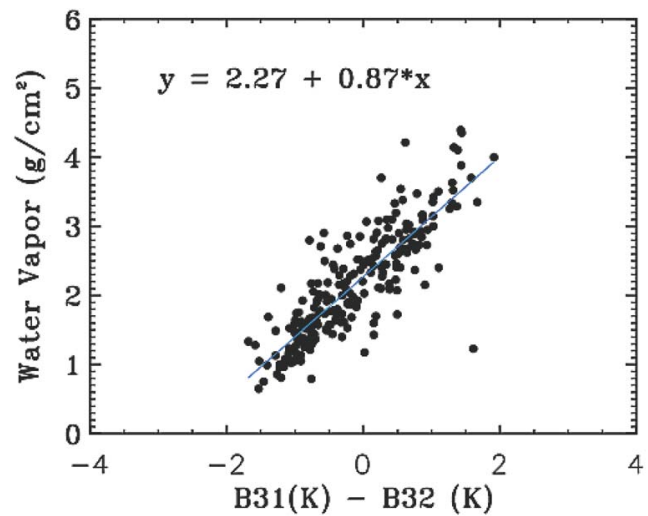

(a)

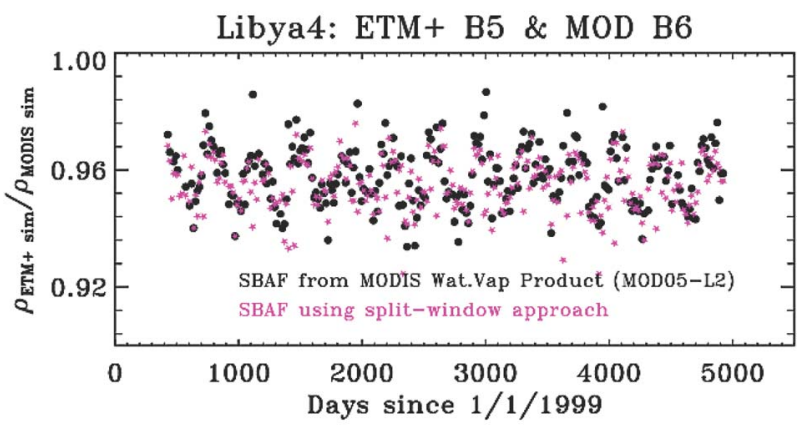

(b)

Fig. 6. (a) Water vapor correction over Libya 4 using the split-window technique. (b) SBAF derived for ETM+ band 5 and MODIS band 6 using both approaches.

the results from the well-established split-window technique is vital. Fig. 6(b) shows the temporal trending for the SBAF derived using both approaches, i.e., the split-window technique and a direct retrieval from the MOD05_L2 product for ETM+ B5 and MODIS B6. Seasonal variations of up to $2 \%$ are evident in the SBAF trending from either approach, which further confirms the impact of the absorption features. The MOD05_L2 products corresponding to the near-simultaneous MODIS-ETM+ scene pairs were processed to derive a timedependent SBAF, which also provides an accurate characterization of the atmospheric water vapor. A close agreement between the two techniques is evident from the figure, with a marginal impact on the long-term biases observed between the two sensors. Since the MODTRAN-based correction involves a real-time input from the MODIS water vapor product, it can be seen as a more preferable approach to account for the spectral mismatch between the two sensors. In the subsequent sections, the results from both methods are presented and analyzed.

\section{RESULTS AND DISCUSSION}

A detailed description of the methodology used to estimate the calibration difference between the two sensors has been discussed in the previous sections. In this analysis, only the near-simultaneous scenes from both sensors were considered to estimate the bias between the two sensors. This section provides a summary of the TOA reflectance trending between the two sensors after accounting for the BRDF and spectral and atmospheric water vapor corrections.
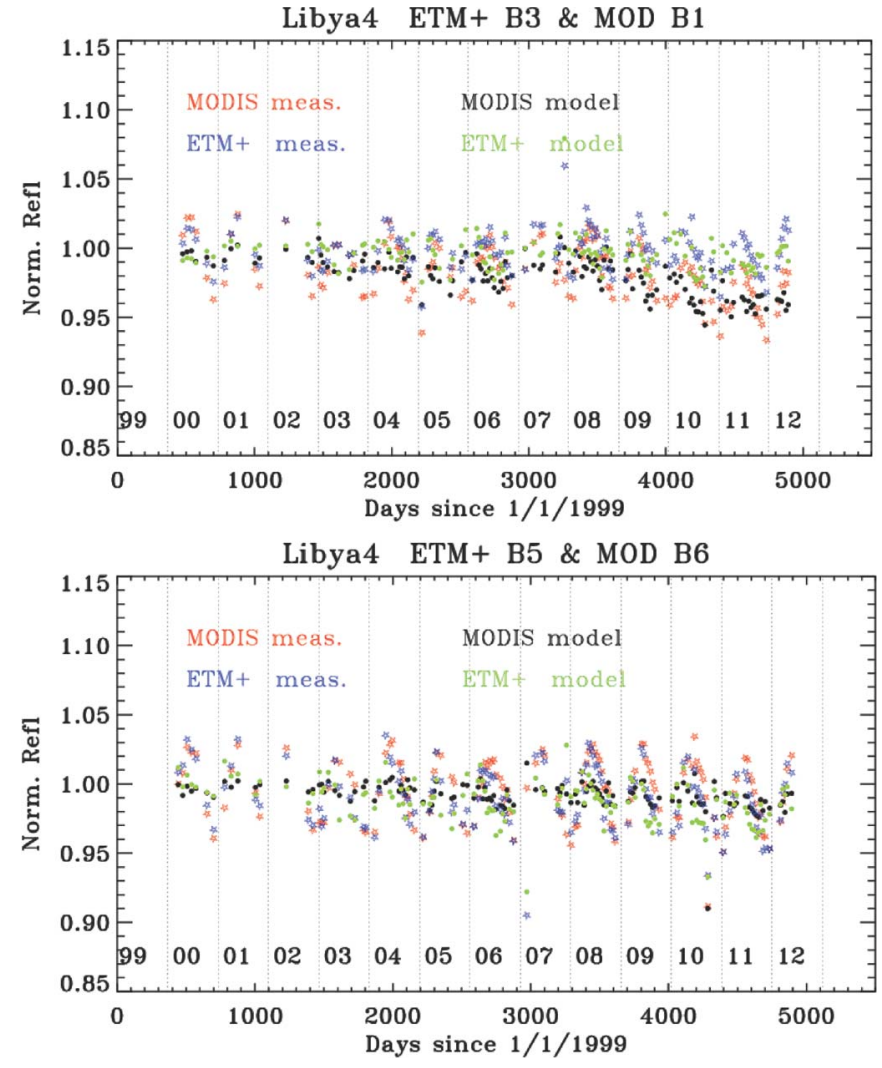

Fig. 7. Impact of BRDF normalization on the TOA reflectance.

\section{A. BRDF Correction}

Fig. 7 shows the normalized reflectance trending for ETM+ bands 3 and 5 and the corresponding MODIS bands 1 and 6. Also, plotted on the same chart is the TOA reflectance after BRDF normalization. In order to enable comparison from all four measurements, each data set is fitted to a simple linear model, and the measurements are normalized to the first value of the fitted model. The TOA measured reflectances (normalized) for ETM+ and MODIS are denoted in red and blue star-shaped symbols, respectively, and the modeled reflectances after BRDF correction (normalized) are denoted in black and green circles, respectively. A large variation of up to $\pm 4 \%$ is seen in the SWIR band pair for ETM+ band 5 and MODIS band 6 , in comparison to the $\pm 2 \%$ variation seen in the VIS band pair of ETM+ band 3 and MODIS band 1. Consequently, a greater improvement is seen in the SWIR band pair, where the variation is reduced to within $2 \%$ post-BRDF normalization. Similar results are seen for other four band pairs, with a greater improvement seen in the SWIR bands compared to the VIS bands. The primary purpose of the BRDF normalization is to remove the impact of seasonal oscillations in the TOA reflectance measurements and to facilitate an accurate characterization of the long-term reflectance changes. The effect of BRDF is seen to be more pronounced at off-nadir viewing angles, where the effectiveness of the correction is seen to be more pronounced. However, since the near-simultaneous overpasses between MODIS and ETM+ are always restricted to near nadir, the need for BRDF normalization, although necessary, is not significant. 

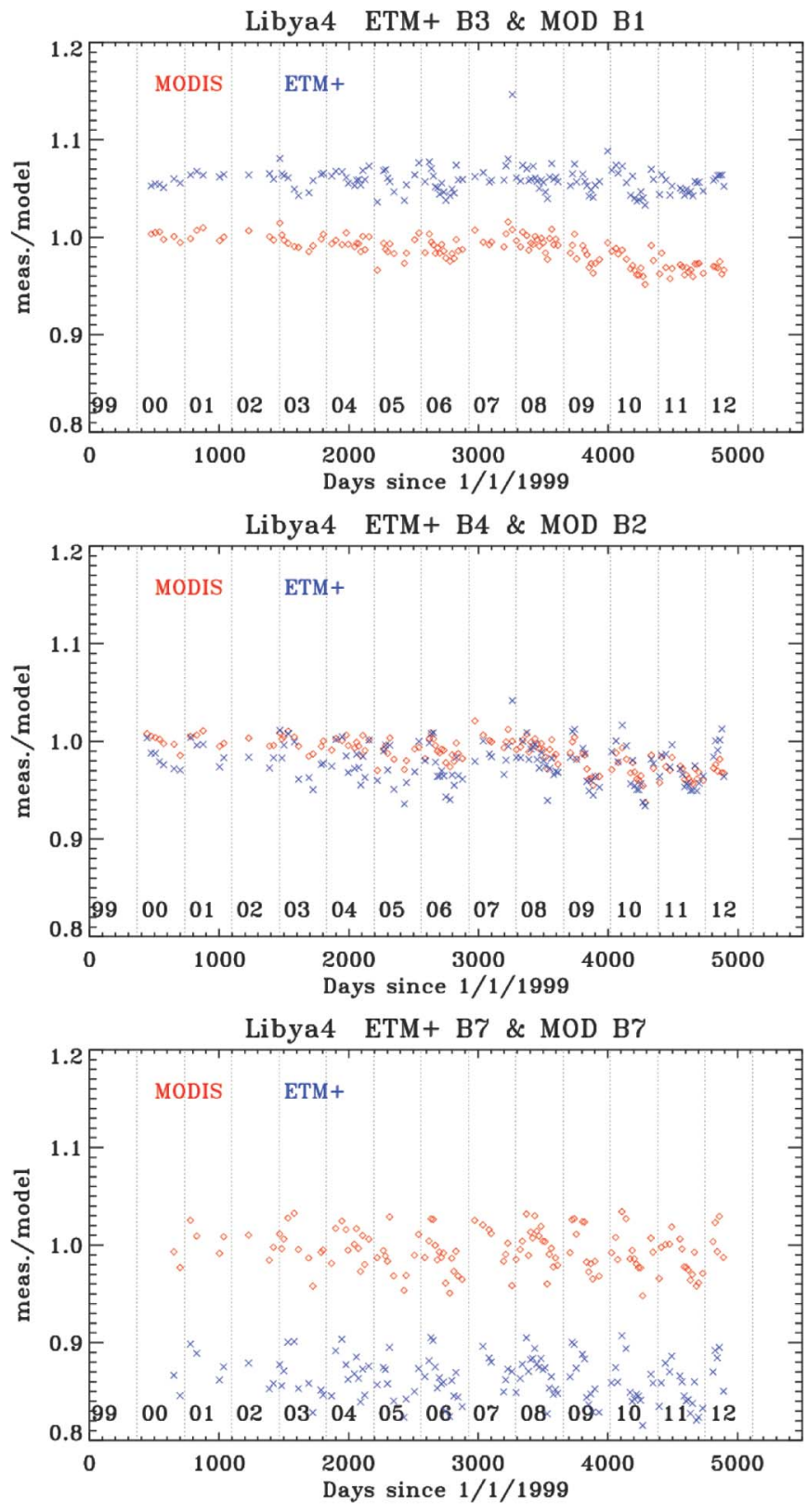

Fig. 8. (a)-(c) MODIS and ETM+ reflectance trending after BRDF normalization. ETM+ reflectances are normalized by the MODIS-based BRDF model.

Fig. 8(a)-(c) shows the TOA reflectance trending plotted as a function of time for both sensors after BRDF normalization. ETM+ band 3, 4, and 7 measurements are denoted in blue plus symbols, and corresponding MODIS measurements are denoted in red diamonds. The three band pairs (ETM+ bands 3, 4, and 7) have been chosen as representatives to demonstrate the effectiveness of this correction. As discussed earlier, the model coefficients were derived from the MODIS measurements and applied to ETM+ TOA reflectance trending. The primary objective of this process is to mitigate the impacts of view geometry differences in order to obtain an accurate estimate of the spectral mismatch between the two sensors. Since the BRDF model coefficients were derived using MODIS measurements and applied back to both sensors, the MODIS measurements are scattered around unity. The offset between the ETM+ and MODIS measurements is primarily due to the RSR mismatch between the two sensors, in addition to the possible calibration bias between the two sensors.

The long-term drift seen in the MODIS band 1 trending is a known artifact due to sensor degradation over $12+$ years on orbit [25]. Various improvements to the current calibration methodology are underway to correct for these drifts, and they will be incorporated in the MODIS Collection 6 products that are to be released later this year. Currently, MODIS Collection 6 is undergoing various science tests and is pending approval from the MODIS Science teams. ETM+ band 3 and MODIS band 1 exhibit a $6 \%$ difference in the TOA reflectance trending after BRDF normalization. This difference can be attributed to the impacts of atmospheric composition on the spectral mismatch, in addition to the calibration differences between the two sensors. A smaller difference is seen in the case of ETM+ band 4 and MODIS band 2, but the differences up to $15 \%$ are seen in the case of ETM+ band 7 and MODIS band 7. As shown in the TOA reflectance trending in Fig. 2, the SWIR bands show the most impact due to BRDF, leading to large variations in the retrieved TOA reflectance on a yearly basis. A residual seasonal pattern is still seen in the ETM+ band 7 and MODIS band 7 pair, which is due to the inadequacy of the semiempirical model in characterizing the impact of the reflectance due to changes in the view geometry.

\section{B. SBAF Correction}

The offset in the TOA reflectance (after BRDF normalization) provides an estimate of the differences caused by the combination of RSR mismatch, the uncertainties caused by atmospheric conditions, and the calibration differences between the two sensors. In the previous section, two methodologies to account for RSR mismatch were formulated: One was using EO-1 Hyperion, and the other was using MODTRAN. The ratio of ETM+ and MODIS reflectance after BRDF normalization is used as a baseline, and spectral mismatch correction using both approaches (EO-1 Hyperion and MODTRAN) is applied. Fig. 9(a)-(c) shows the ETM+/MODIS ratio for selected bands after BRDF normalization (denoted in blue), EO-1 Hyperionbased SBAF correction applied to the BRDF corrected ratios (denoted in orange), and MODTRAN-based SBAF correction applied to BRDF corrected ratios (denoted in black). A unity value of the ratio indicates a perfect agreement between the two sensors. The results after BRDF and spectral correction for the near-simultaneous scenes for ETM+ bands 3, 4, and 7 are shown in Fig. 9, and the results for all of the six spectral bands are summarized in Table IV. For the bands with a water vapor absorption feature (ETM+ bands 4 and 7 in Fig. 9), the MODTRAN-based spectral correction results in a better agreement between the two sensors. For ETM+ band 4, the ratio before correction is within about 2\%; however, Hyperionbased SBAF indicates an overcorrection, after which the ratio is around 5\% higher. In addition to the absence of nearsimultaneous Hyperion acquisitions, the shape of the hyperspectral profile derived from EO-1 Hyperion is assumed to be a reasonably accurate estimate of the observed ground target. However, long-term degradation has been reported across the 

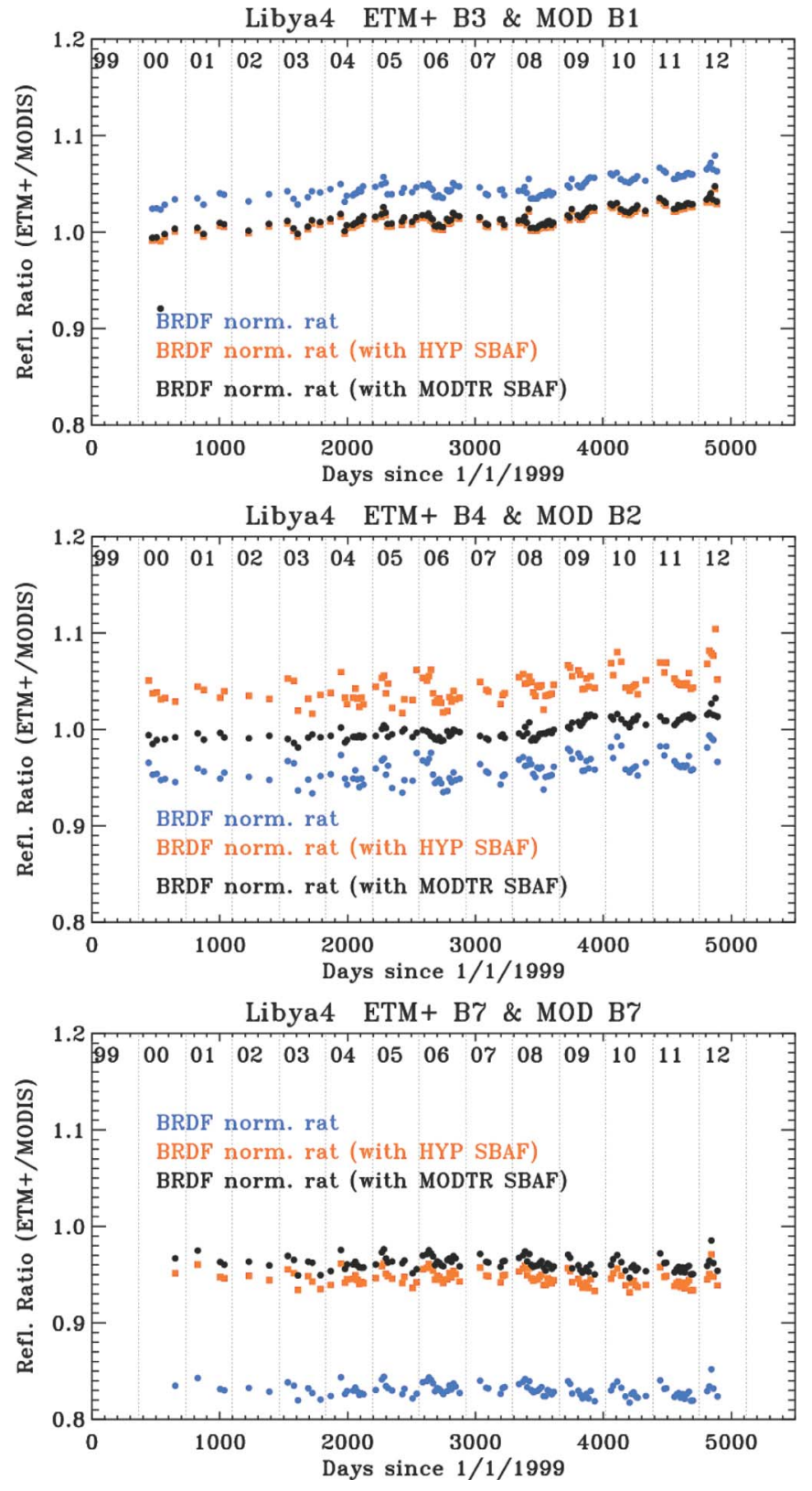

Fig. 9. (a)-(c) ETM+/MODIS ratio after BRDF and spectral correction.

Hyperion spectral bands which, in turn, impact the shape of the retrieved spectral profile [20]. For ETM+ bands 3 and 7, the correction based on MODTRAN and EO-1 Hyperion provides a reasonable agreement. Assuming that the ground target is spectrally and temporally stable, lifetime correction using a hyperspectral profile from EO-1 Hyperion can provide reasonable results at wavelengths not impacted by the water vapor absorption feature. These bands (ETM+ band 4 and MODIS band 2) require a more accurate representation of the ground spectral signature, which can be obtained using MODTRAN 5.0 and real-time information of the atmospheric water vapor derived from the MODIS channels.

The impacts of the spectral mismatch correction (using EO-1 Hyperion and MODTRAN) on the ETM+/MODIS ratio after BRDF normalization need to be carefully quantified. In order to provide a quantitative estimate of the calibration differences between the two sensors, a calendar year average is calculated for all of the three cases (with BRDF correction, with BRDF and Hyperion SBAF, and with BRDF and MODTRAN SBAF) using the data presented in Fig. 9. The value of this ratio (yearly averaged) close to unity indicates a perfect agreement between the two sensors; however, if the reflectances (post-BRDF and spectral mismatch correction) agree within the calibration uncertainty specification of either sensor, a reasonable agreement between the two sensors can be concluded. Finally, a percent difference in the TOA reflectance after each correction is summarized in Table IV. The three representative years are chosen so that an estimate of the differences at the early, mid, and late timelines of both missions can be obtained. The ETM+/MODIS ratio after BRDF normalization is denoted in this table as "BRDF." The value for each year is obtained by a simple yearly average of all ETM+/MODIS ratios after BRDF normalization over the near-simultaneous scenes acquired from the calendar year. The spectral mismatch and water vapor correction based on EO-1 Hyperion and MODTRAN is applied to these BRDF normalized ratios, and the corrected ratios are denoted under the columns "HYP" and "MODTRAN."

For ETM+ band 1 and MODIS band 3, the difference after BRDF correction varies from $2.5 \%$ to $6.7 \%$, which is due to the long-term drift seen in the shorter wavelength bands. As stated earlier, all of the results used in this paper are derived using the MODIS Collection 5 products, and the long-term drift is an artifact caused by inaccurate gain characterization in the MODIS VIS bands. The upcoming Collection 6 algorithm uses response trending from pseudo-invariant ground targets to supplement the measurements from the onboard calibrators. A similar temporal drift (after BRDF correction) is also evident in MODIS bands 1 and 2 with the corresponding ETM+ bands. Comparatively, the SWIR bands (MODIS bands 6 and 7) exhibit smaller differences, with the difference (after BRDF correction) varying from $10 \%$ (in 2001) to about $11 \%$ (in 2010) and $16.5 \%$ (in 2001) to $17.2 \%$ (in 2010). The spectral mismatch correction using either methodology provides a compensation for the offset observed in the reflectance trends of the two sensors; however, it bears no impact on the long-term drift observed in either sensor. The results from Hyperion- and MODTRANbased SBAFs generally provide an improvement in terms of mitigating the impacts due to spectral mismatch; however, a significant disagreement is seen between the two corrections. The results from 2001 are used to evaluate the agreement between the two corrections since they are not contaminated by any temporal drifts. A difference up to $4 \%$ is observed in the case of the ETM+ band 1 and MODIS band 3 pair, and a better agreement is observed for the remaining band pairs. The MODTRANbased SBAF has the near-simultaneous water vapor information embedded in its calculation, and hence, it is likely to accurately characterize the daily variations in the SBAF.

In comparison, the EO-1 Hyperion provides the exact spectral signature of the Libya 4 site but has limited nearsimultaneous overpasses with ETM+ and MODIS. In addition, the underlying assumption in the usage of the EO-1 Hyperion data is the assumption that the prelaunch calibration coefficients are adequate in characterizing the sensor's changes over a decade. Since no quantitative evidence regarding the calibration 
TABLE IV

TOA Reflectance Percentage Differences After BRDF And SBAF Correction

\begin{tabular}{|c|c|c|c|c|c|c|c|c|c|}
\hline & \multicolumn{3}{|c|}{2001 (early) } & \multicolumn{3}{c|}{2005 (mid) } & \multicolumn{3}{c|}{2010 (late) } \\
\hline Band-Pair & BRDF & $\begin{array}{c}\text { BRDF+ } \\
\text { HYP }\end{array}$ & $\begin{array}{c}\text { BRDF+ } \\
\text { MODT }\end{array}$ & BRDF & $\begin{array}{c}\text { BRDF+ } \\
\text { HYP }\end{array}$ & $\begin{array}{c}\text { BRDF+ } \\
\text { MODT }\end{array}$ & BRDF & $\begin{array}{c}\text { BRDF+ } \\
\text { HYP }\end{array}$ & $\begin{array}{c}\text { BRDF+ } \\
\text { MODT }\end{array}$ \\
\hline $\begin{array}{c}\text { ETM+ B1 \& } \\
\text { MOD B3 }\end{array}$ & -2.5 & 4.1 & 0.1 & -4.7 & 2.0 & -2.0 & -6.7 & 0.2 & -3.9 \\
\hline $\begin{array}{c}\text { ETM+ B2 \& } \\
\text { MOD B4 }\end{array}$ & -5.4 & -2.0 & -4.2 & -6.3 & -2.9 & -5.2 & -6.3 & -2.9 & -5.2 \\
\hline $\begin{array}{c}\text { ETM+ B3 \& } \\
\text { MOD B1 }\end{array}$ & -3.5 & -0.2 & -0.5 & -4.5 & -1.2 & -1.5 & -5.0 & -1.7 & -2.0 \\
\hline $\begin{array}{c}\text { ETM+ B4 \& } \\
\text { MOD B2 }\end{array}$ & 4.4 & -3.9 & 0.6 & 4.4 & -4.0 & 0.2 & 3.2 & -5.3 & -0.8 \\
\hline $\begin{array}{c}\text { ETM+ B5 \& } \\
\text { MOD B6 }\end{array}$ & 10.0 & 5.3 & 6.0 & 10.7 & 6.0 & 6.3 & 11.0 & 6.4 & 6.8 \\
\hline $\begin{array}{c}\text { ETM+ B7 \& } \\
\text { MOD B7 }\end{array}$ & 16.5 & 4.8 & 3.3 & 16.8 & 5.1 & 3.6 & 17.2 & 5.7 & 4.2 \\
\hline
\end{tabular}

inconsistencies of EO-1 Hyperion is available, the disagreement between the EO-1 Hyperion and MODTRAN-based SBAF contributes to the uncertainty of the cross-calibration between the two sensors. Using the MODTRAN-based SBAF as a metric, the following observations can be made in regard to the agreement between the two sensors. It can be seen that ETM+ band 1 and MODIS band 3 agreed to within $2 \%$ up to 2005 , after which the drift in the MODIS band 3 trending biases the agreement between the two sensors to nearly $4 \%$. A similar pattern is observed in the results of ETM+ bands 3 and 4. For the SWIR bands, the improvement after spectral correction using either approach is noticeable. Band 4 of ETM+ has a water vapor absorption feature in its RSR, which is notably absent from the MODIS RSR, and the calibration difference is generally within $1 \%$. For bands 5 and 7 , the agreement between the two sensors is around $10 \%$ and $16 \%$, respectively, which, after either approach of spectral correction, reduces to around $6 \%$ and $4 \%$.

\section{Future Improvements}

Among the various techniques used for sensor crosscalibration, comparing near-simultaneous scene pairs over a pseudo-invariant target, described in this paper, is an effective approach to compare the reflectance differences observed by sensors [16]. The various uncertainties associated with the dayto-day observations, such as variations in the atmospheric conditions over the site, yield an insignificant result regarding the calibration differences between the two sensors. To overcome this limitation, multitemporal observations over a stable target can be an effective tool to evaluate the long-term stability and calibration differences between sensors. In this paper, the Libya 4 site was used to evaluate the calibration differences between the spectrally matching RSB of the MODIS and ETM+ sensors. A semiempirical approach has been used to mitigate the impacts of site BRDF in the observed reflectance by each sensor. Site BRDF characterization eliminates the impacts due to view geometry observed in the TOA reflectance trending of both sensors. The impacts of columnar atmospheric water vapor content can have a significant impact of up to $10 \%$ at certain wavelengths and need to be accounted for in order to perform an accurate cross-calibration between any two sensors. Due to lack of availability of near-simultaneous hyperspectral observations, a technique using MODTRAN 5.0 along with real-time water vapor information is used to characterize this effect. Table III provides a detailed summary of the number of near-simultaneous scenes used in this analysis. Since Libya 4 is a very dry desert target, the impact of variations in the columnar atmospheric water vapor content is confined only to certain wavelengths. The real-time columnar water vapor derived using the MOD05_L2 product provides an impact of the daily variations in the atmosphere on the derived SBAF. The SBAF derived from the product was also validated with the correction derived using the well-established split-window algorithm. The difference in the SBAF derived from EO-1 Hyperion and MODTRAN 5.0 contributes to the uncertainty in assessment of the biases between the water vapor sensitive band pairs.

As stated earlier, all of the analysis was performed using the MODIS Collection 5 products. The major source of difference between the two sensors in the VIS/NIR bands (bands 1-4) is caused by the long-term drift in the MODIS TOA reflectance, as seen in Table IV. The long-term drift in the MODIS TOA reflectance in these bands is a known phenomenon caused by the inadequate characterization of the on-orbit gain change. Significant improvements to the MODIS RSB calibration algorithm have been undertaken to mitigate these observed long-term drifts, and the upcoming Collection 6 algorithm is expected to yield a significantly better agreement between the two sensors. The MODIS Collection 6 calibration coefficients are currently undergoing various science tests, and the entire mission of Terra MODIS scenes will be reprocessed thereafter. In comparison to the VIS/NIR bands, the SWIR band pair (ETM+ band 5 and MODIS band 6) does not show a significant temporal drift in either sensor; however, the difference between the two sensors after spectral correction exceeds $6 \%$ in ETM+ band 5 and $4 \%$ in ETM+ band 7. In the case of band 7 pair, an added uncertainty of $2 \%$ (as described in Table IV) can be attributed to the differences induced due to solar irradiance models of the two sensors. The presence of electronic crosstalk and optical leak has been confirmed for the Terra MODIS SWIR bands since prelaunch analysis. Various algorithms have been developed and implemented to characterize the out-of-band signal contribution; however, residual impacts of the crosstalk still persist. Hence, an additional $\pm 1 \%$ uncertainty has been specified for the MODIS SWIR band TOA reflectance product. 
In addition, extension of this methodology to measurements acquired from other pseudo-invariant targets such as Dome Concordia and the Sonoran desert will provide additional insight in the calibration differences between the two sensors. A comprehensive assessment of the TOA reflectance differences between the spectrally matching RSB of MODIS and ETM+ is provided, which will greatly benefit the science community. The developed technique can also be extended to estimate the calibration differences from near-simultaneous measurements from other EO sensors such as Aqua MODIS, Terra Multi-angle Imaging SpectroRadiometer, Landsat 5 Thematic Mapper, and Suomi National Polar-orbiting Partnership Visible Infrared Imaging Radiometer Suite.

\section{CONCLUSion}

This paper has examined the calibration consistency of the RSBs of Terra MODIS and Landsat 7 ETM+ using nearsimultaneous Libya 4 observations. The differences seen in the TOA reflectance trending for the spectrally matching band pairs have been attributed to inconsistencies in the cross-sensor comparison methodology. As an improvement, a semiempirical BRDF model was developed and applied to mitigate the impacts due to view geometry differences. In addition, correction for spectral response mismatch between the two sensors was implemented using hyperspectral observations from EO-1 Hyperion as well as simulated spectra derived using MODTRAN. A real-time correction for the various water vapor absorption features in the ETM+ RSR was incorporated with the widely used split-window technique, which uses the infrared channels to estimate the water vapor content. The BT difference between MODIS bands 31 and 32 provided essential information on the water vapor concentration in the atmosphere. As a result, the relationship between MODTRAN water vapor simulation and spectral correction factors has enabled an improved accuracy of the SBAF.

In general, a better agreement was seen between the SWIR bands than the shorter wavelength bands of both sensors. The results indicate that the temporal bias of about $4 \%$ is observed in ETM+ band 1 and MODIS band 3, which is attributed to the long-term degradation seen in the MODIS visible bands. ETM+ bands 3, 4, 5, and 7 agree with the corresponding MODIS bands within 5\%. MODTRAN-based spectral correction indicates a better agreement in comparison with the EO-1 Hyperion-based spectral correction, particularly in ETM+ bands 4, 5, and 7, which have the presence of a water vapor absorption in their RSR. Although the application of the techniques presented in this paper was focused on comparing near-simultaneous observations from L7 ETM+ and Terra MODIS RSB, it can be easily extended and applied to evaluate the differences between any two optical EO sensors.

\section{ACKNOWLEDGMENT}

The authors would like to thank T. Adamson (SGT) for providing helpful comments in the technical review of this paper. The work performed by G. Chander is under U.S. Geological Survey contract G10PC00044. The detailed comments from the anonymous reviewers were extremely helpful in improving the quality and readability of this paper.

\section{REFERENCES}

[1] X. Xiong, B. N. Wenny, and W. L. Barnes, "Overview of NASA Earth observing systems Terra and Aqua Moderate Resolution Imaging Spectroradiometer instrument calibration algorithms and on-orbit performance," J. Appl. Remote Sens., vol. 3, p. 032501, 2009.

[2] X. Xiong, J. Sun, W. Barnes, V. Salomonson, J. Esposito, H. Erives, and B. Guenther, "Multi-year on-orbit calibration and performance of Terra MODIS reflective solar bands," IEEE Trans. Geosci. Remote Sens., vol. 45, no. 4, pp. 879-889, Apr. 2007.

[3] B. L. Markham, J. L. Barker, E. Kaita, J. Sieferth, and R. Morfitt, "Onorbit performance of the Landsat-7 ETM+ radiometric calibrators," Int. J. Remote Sens., vol. 24, no. 2, pp. 265-285, 2003.

[4] Landsat-7 Science Data Users Handbook, NASA/GSFC, Greenbelt, MD, 2011.

[5] B. L. Markham, M. O. Haque, J. A. Barsi, E. Micijevic, D. L. Helder, K. J. Thome, D. Aaron, and J. S. Czapla-Myers, "Landsat-7 ETM+: 12 years on-orbit reflective-band radiometric performance," IEEE Trans. Geosci. Remote Sens., vol. 50, no. 5, pp. 2056-2062, May 2012.

[6] G. Chander, X. Xiong, T. Choi, and A. Angal, "Monitoring on-orbit calibration stability of the Terra MODIS and Landsat 7 ETM+ sensors using pseudo-invariant test sites," Remote Sens. Environ., vol. 114, no. 4, pp. 925-939, Apr. 2010.

[7] A. Angal, X. X. Xiong, T. Y. Choi, G. Chander, and A. Wu, "Using the Sonoran and Libyan desert test sites to monitor the temporal stability of reflective solar bands for Landsat 7 Enhanced Thematic Mapper Plus and Terra Moderate Resolution Imaging Spectroradiometer sensors," J. Appl. Remote Sens., vol. 4, no. 1, pp. 043525-1-043525-12, 2010.

[8] A. Berk, G. P. Anderson, P. K. Acharya, L. S. Bernstein, L. Muratov, J. Lee, M. Fox, S. M. Adler-Golden, J. H. Chetwynd, M. L. Hoke, R. B. Lockwood, J. A. Gardner, T. W. Cooley, C. C. Borel, and P. E. Lewis, "MODTRAN 5: A reformulated atmospheric band model with auxiliary species and practical multiple scattering options: Update," in Proc. SPIE, 2005, vol. 5806, pp. 662-1565.

[9] H. Cosnefroy, M. Leroy, and X. Briottet, "Selection and characterization of Saharan and Arabian desert sites for the calibration of optical satellite sensors," Remote Sens. Environ., vol. 58, no. 1, pp. 101-114, Oct. 1996.

[10] C. R. N. Rao and J. Chen, "Post-launch calibration of the visible and near infrared channels of the Advanced Very High Resolution Radiometer on NOAA-14 spacecraft," Int. J. Remote Sens., vol. 17, no. 14, pp. 2743 2747, 1996.

[11] G. Chander, J. B. Christopherson, G. L. Stensaas, and P. M. Teillet, "Online catalog of world-wide test sites for the post-launch characterization and calibration of optical sensors," in Proc. 58th Int. Astron. Congr., Hyderabad, Andhra Pradesh, 2007, pp. 2043-2051.

[12] S. Lachérade, B. Fougnie, P. Henry, and P. Gamet, "Cross-calibration over desert sites: Description, methodology and operational implementation," IEEE Trans. Geosci. Remote Sens., vol. 51, no. 3, pp. 1098-1113, Mar. 2013.

[13] A. Wu and Q. Zhong, "A method for determining the sensor degradation rates of NOAA AVHRR channels 1 and 2," J. Appl. Meteorol., vol. 33, no. 1, pp. 118-128, Jan. 1994.

[14] J. L. Roujen, M. J. Leroy, and P. Y. Deschamps, "A bidirectional reflectance model of the Earth's surface for the correction of remote sensing data," J. Geophys. Res., vol. 97, no. D18, pp. 20 455-20 468, Jan. 1992.

[15] D. L. Smith, C. T. Mutlow, and C. R. Nagaraja Rao, "Calibration monitoring of the visible and near-infrared channels of the along-track scanning radiometer-2 by use of stable terrestrial sites," J. Appl. Opt., vol. 41, no. 3, pp. 515-523, Jan. 2002.

[16] X. Xiong, A. Wu, B. Wenny, J. Choi, and A. Angal, "Progress and lessons from MODIS calibration inter-comparison using ground test sites," Can. J. Remote Sens. Special Issue, vol. 36, no. 5, pp. 540-552, 2010.

[17] P. M. Teillet, G. Fedosejevs, K. J. Thome, and J. L. Barker, "Impacts of spectral band difference effects on radiometric cross-calibration between satellite sensors in the solar-reflective spectral domain," Remote Sens. Environ., vol. 110, no. 3, pp. 393-409, Oct. 2007.

[18] J. Pearlman, P. Barry, C. Segal, J. Shepanski, D. Beiso, and S. Carman, "Hyperion, a space-based imaging spectrometer," IEEE Trans. Geosci. Remote Sens., vol. 41, no. 6, pp. 1160-1173, Jun. 2003.

[19] "EO-1 Weekly Reports," NASA/GSFC, Greenbelt, MD, 2011.

[20] G. Chander, N. Mishra, D. Helder, D. Aaron, A. Angal, T. Choi, X. Xiong, and D. Doelling, "Applications and limitations of the spectral 
band adjustment factors (SBAF) for cross-calibration," IEEE Trans. Geosci. Remote Sens., vol. 51, no. 3, pp. 1267-1281, Mar. 2013.

[21] A. Wu, A. Angal, and X. Xiong, "Using MODIS to calibrate NOAA series AVHRR reflective solar channels," in Proc. SPIE -Earth Observ. Syst. XVI, 2011, vol. 8153, no. 815317.

[22] F. Yu and X. Wu, "Water vapor correction to improve the operational calibration for NOAA AVHRR/3 channel $2(0.85 \mu \mathrm{m})$ over a desert target," Can. J. Remote Sens., vol. 36, no. 5, pp. 514-526, 2010.

[23] Y. J. Kaufman and B. C. Gao, "Remote sensing of water-vapor in the near IR from EOS/MODIS," IEEE Trans. Geosci. Remote Sens., vol. 30, no. 5, pp. 871-884, Sep. 1992.

[24] E. F. Vermote and N. Z. Saleous, "Calibration of NOAA16 AVHRR over a desert site using MODIS data," Remote Sens. Environ., vol. 105, no. 3, pp. 214-220, Dec. 2006.

[25] D. Wang, D. Morton, J. Masek, A. Wu, J. Nagol, X. Xiong, R. Levy, E. Vermote, and R. Wolfe, "Impact of sensor degradation on MODIS NDVI time series," Remote Sens. Environ., vol. 116, pp. 55-61, Apr. 2012.

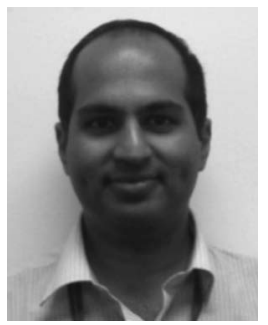

Amit Angal received the M.S. degree in electrical engineering from South Dakota State University, Brookings, SD, USA.

$\mathrm{He}$ is currently a Senior Instrument Engineer with Science Systems and Applications, Inc., Lanham, MD, USA, primarily working on the radiometric characterization and calibration of the reflective solar bands of the MODIS instruments onboard the Terra and Aqua spacecrafts. His research interests include sensor cross-calibration and validation.

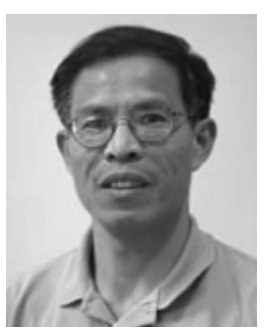

Xiaoxiong (Jack) Xiong (M'12) received the B.S. degree in optical engineering from Beijing Institute of Technology, Beijing, China, and the Ph.D. degree in physics from the University of Maryland, College Park, MD, USA.

$\mathrm{He}$ is an Optical Physicist with the NASA Goddard Space Flight Center (GSFC), Greenbelt, MD, USA. He is currently serving as the MODIS Project Scientist and the technical lead for both the MODIS Characterization Support Team and the VIIRS Calibration Support Team. Before joining the NASA/GSFC, he had also worked in the fields of optical instrumentation, nonlinear optics, laser and atomic spectroscopy, and resonance ionization mass spectrometry at universities, at industry, and at the National Institute of Standards and Technology, Gaithersburg, MD, USA.

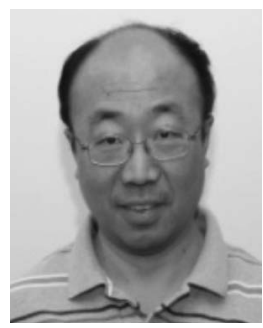

Aisheng Wu received the B.S. degree in atmospheric science from the University of Science and Technology of China, Hofei, China, the M.Sc. degree in atmospheric remote sensing from the Institute of Plateau Atmospheric Physics, Chinese Academy of Sciences, Lanzhou, China, and the Ph.D. degree in bio-meteorology/soil physics from the University of British Columbia, Vancouver, BC, Canada.

$\mathrm{He}$ is currently a Senior Scientist with the MODIS and VIIRS Characterization and Support Teams/ Sigma Space Corporation, Lanham, MD, USA.

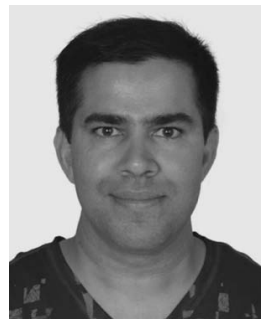

Gyanesh Chander (M'02) received the M.S. degree in electrical engineering and the Ph.D. degree in geospatial science and engineering with specialization in remote sensing engineering from South Dakota State University, Brookings, SD, USA, in 2002 and 2011, respectively.

He is currently a Principal Systems Engineer with SGT, Inc., at the U.S. Geological Survey Earth Resources Observation and Science (EROS) Center, Sioux Falls, SD, USA. His primary responsibilities at EROS include satellite sensor characterization and calibration research to support on-going radiometric projects.

Dr. Chander is an active member of the international Committee of Earth Observation Satellites Working Group Calibration Validation and serves on the Global Space-based Inter-Calibration System Executive Panel.

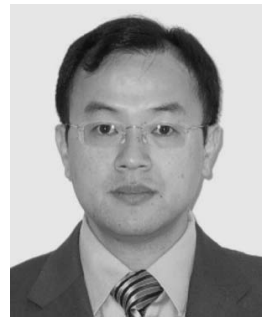

Taeyoung Choi received the B.S. degree in electronics from Kon-Kuk University, Seoul, Korea, and the M.S. degree in electrical engineering from South Dakota State University, Brookings, SD, USA. He is currently working toward the Ph.D. degree in earth systems and geoinformation sciences at Gorge Mason University, Fairfax, VA, USA.

He is currently a member of the MODIS Characterization Support Team, performing radiometric, spectral, and spatial calibration in the reflective solar bands with Sigmaspace Corporation. He has been working in remote sensing, instrument calibration, and data applications with various sensors such as IKONOS, QuickBird, TM, ETM+, ALI, Hyperion, and MODIS since 1999. 